\title{
Celebrating multidisciplinarity
}

This first issue of the South African Journal of Science in 2021 contains a wealth of multidisciplinary articles that are interesting to read while also broadening and deepening topics that are significant to the South African research agenda. While special issues highlight particular topics that consolidate research in a particular field, the Journal's strength lies in its multidisciplinary breadth. We also value the fact that our authors are varied - some are well established in their fields, while others are new to academic publishing and give us the privilege of publishing their first article.

This issue contains a rich variety of Commentaries, which provide perspectives on the link between research and policy, on artificial intelligence and bioinformatics, ecological and social research in the Karoo and other regions, and the impact of COVID-19 on child development. We are also delighted to publish a profile of Professor David Mason of the University of the Witwatersrand, one of South Africa's leading computer scientists and mathematicians.

However, it is the Review and Research Articles that identify this journal issue as remarkable, not only for its content, but for its flagging of many of the Sustainable Development Goals that are crucial to the future wellbeing of southern Africa and Africa. The article on transdisciplinary research in Namibia by Robert Luetkemeier and colleagues provides direction for others in this complex field that crosses and integrates disciplinary boundaries and holds both promise and difficult challenges. Research Letters by Robin Fisher, Andrew Skowno and co-authors, and Loewan Erasmus et al., speak to environmental research in the marine and savanna environments but also deal with habitat changes in our ecological systems more generally. The Research Article by Tionhonkélé Soro and co-authors identifies the fire hotspots in Côte d'Ivoire, an African country on which more research is always welcome. The highaltitude work of Maqsooda Mahomed, of Dakalo Mashao, and of Moshe Mosotho and their co-authors is a reminder of how much more there is to be discovered about the characteristics of the Earth's atmosphere and how best we may sustain it. The rich and always-fascinating fossil heritage of the sub-continent appears in the hominin work of Travis Pickering and the small mammal work of Thalassa Matthews and their collaborators. Although, for obvious reasons, COVID-19 has gained the most medical attention over the past year, combating and controlling HIV remains the country's other great medical challenge. Mohammed Majam et al. present comparative work on HIV self-test devices and mark progress in this regard. What benefits there may be for higher education through targeted and more generous funding has been analysed by Temwa Moyo and his colleague, and Tanja Verster and her team have been able to investigate important aspects of the home loan industry through her case study.

It is also worth noting the enormous variety of collaborations in all these contributions and to celebrate this networking. Collaboration is evident not only among universities in South Africa, as might be expected - Wits, UCT, UP, UJ, UWC, Rhodes, Free State, North-West, UKZN, Stellenbosch, Nelson Mandela, Mpumalanga, Unisa, Fort Hare - but also in other parts of Africa - Namibia, Nigeria, Zimbabwe and Côte d'Ivoire - and even further abroad. The geographical range of institutional cooperation is impressive: Madison Wisconsin, Colorado, Clemson South Carolina,
Birmingham Alabama, Princeton and Minnesota in the USA, Budapest in Hungary, Belfast, Cornwall and Lancaster in the UK, Leuven in Belgium, Bergen in Norway, and Frankfurt in Germany. Moreover, it is also exciting to see collaborations with state structures, such as the South African National Space Agency, the South African Environmental Observation Network, the South African National Biodiversity Institute, Ezemvelo KZN Wildlife and Iziko Museums of South Africa. There is also collaboration with the private sector: ABSA and FNB with Verster et al., and Halteres Associates in San Francisco with Majam et al.

The importance and value of a multidisciplinary journal is not only in that it publishes a diversity of research, but also in that it reaches audiences that, in the ordinary course of their specialised reading, might not be exposed to unfamiliar research areas and from which they can learn much. Journals like the South African Journal of Science play a role in breaking down the silos of research and encourage a broad distribution of knowledge to many cohorts of readers who are experts in their own fields, but avid for wider knowledge.

That we are able to present this cornucopia of research is due to the efforts of our team of Associate Editors who shepherd manuscripts through the process of peer review, passing on the comments of peer reviewers in helpful ways and suggesting improvements from their own knowledge and research. This year has not been easy for them as they have grappled with online teaching, a disrupted research agenda of their own, and general scholarly and personal uncertainty. We are also grateful to all our peer reviewers who have taken time and trouble to assess manuscripts for their quality and who are often willing to look at work repeatedly in order to ensure appropriate improvement before publication. During 2020 and the COVID-19 pandemic, many reviewers were even more over-stretched than usual, carrying the burden of teaching online and the uncertainty of the trajectory of the academic enterprise. We therefore doubly appreciate their expertise, willingly provided as volunteers at a difficult time. While our authors and their institutions benefit financially and reputationally from publication in accredited, peer-reviewed, and well-cited journals, those editors and peer reviewers who make this possible do not.

Cumulatively, these contributions and connections attest to the vigour diversity, and quality of scholarship and academic excellence in our part of the world and we very much hope that you will enjoy reading this issue of the South African Journal of Science.

As I end my term of office at the helm of the South African Journal of Science, it is a great pleasure to introduce the incoming Editor-in-Chief, Professor Leslie Swartz, a graduate of the University of Cape Town and currently Professor of Psychology at Stellenbosch University. Widely published, internationally well known, and the recipient of many awards, Leslie has been involved in journal publishing in many capacities for decades. He is the Founding Editor and former Editor-in-Chief of the African Journal of Disability and the majority of his research lies in the fields of mental health, disabilities studies, and access to health care for vulnerable groups in Africa. We wish him a long and rewarding association with the South African Journal of Science.

HOW TO CITE:

Carruthers J. Celebrating multidisciplinarity. S Afr J Sci. 2021;117(1/2), Art. \#9391. https://doi.org/10.17159/sajs.2021/9391 